\title{
Fertilização com boro e zinco no solo em complementação à aplicação via foliar em laranjeira Pêra ${ }^{(1)}$
}

\begin{abstract}
José Antônio Quaggio( ${ }^{(2)}$, Dirceu Mattos Junior ${ }^{(3)}$, Heitor Cantarella ${ }^{(2)}$ e Aprigio Tank Junior ${ }^{(4)}$
Resumo - As deficiências de boro (B) e zinco (Zn) são as mais freqüentes na citricultura brasileira e há escassez de conhecimento sobre critérios de diagnóstico e manejo desses nutrientes nessa cultura. A aplicação foliar tem sido a forma tradicional de fornecimento desses nutrientes, a despeito da baixa redistribuição na planta cítrica. O objetivo deste trabalho foi avaliar a eficiência da aplicação complementar de B e Zn no solo em comparação com a aplicação via foliar e estabelecer curvas de calibração de análises de solo e de folhas com a produtividade da laranjeira Pêra. Os tratamentos foram arranjados em delineamento fatorial $4^{2}$, com três repetições. Foram aplicadas no solo as doses anuais de 0, 2, 4 e $6 \mathrm{~kg} \mathrm{ha}^{-1} \mathrm{de} \mathrm{B}$ (ácido bórico) e $\mathrm{Zn}$ (sulfato de zinco), em complemento à adubação foliar. A produção de frutos aumentou significativamente com a aplicação de B no solo até a dose de $4 \mathrm{~kg} \mathrm{ha}^{-1}$, enquanto a aplicação de Zn no solo mostrou-se pouco eficiente. As doses de B afetaram a qualidade dos frutos. A produtividade máxima foi obtida com teor de $\mathrm{B}$ no solo de $1,0 \mathrm{mg} \mathrm{dm}^{-3}$, e na folha de cerca de $300 \mathrm{mg} \mathrm{kg}{ }^{-1}$. A aplicação foliar de B, apesar de evitar os sintomas típicos de deficiência, não otimizou a produtividade e a qualidade dos frutos, enquanto a aplicação foliar de $\mathrm{Zn}$ mostrou-se eficiente. Curvas de calibração de análises de solo e de folhas mostraram a necessidade de rever as classes de interpretação desses micronutrientes na citricultura.
\end{abstract}

Termos para indexação: citro, micronutriente, aplicação de fertilizante, fertilidade do solo, rendimento.

\section{Boron and zinc application on soil as complement to leaf spray on orange Pera trees}

\begin{abstract}
Boron (B) and zinc ( $\mathrm{Zn})$ are the most deficient micronutrients in the Brazilian's citrus industry. Worldwide, there is limited information about diagnostic criteria and management of these nutrients to the citrus crop. Leaf spray has been the usual form of application of these nutrients, despite their low redistribution into the citrus trees. The present work was carried out during four years in order to establish responses of citrus yield to complementary soil application of B and $\mathrm{Zn}$ compared to the traditional leaf spray, and to improve diagnostic tools for micronutrient recommendation based on soil and leaf analyses. The experiment was a $4^{2}$ factorial design, with three replications, with four yearly rates $\left(0,2,4\right.$ and $\left.6 \mathrm{~kg} \mathrm{ha}^{-1}\right)$ of $\mathrm{B}$, as boric acid, and $\mathrm{Zn}$, as zinc sulfate. A significant response to soil $\mathrm{B}$ application was observed in two years compared to the conventional spray treatment, which did not improve yield and fruit quality. Maximum yield was reached at $4 \mathrm{~kg} \mathrm{ha}^{-1} \mathrm{~B}$ rate, which increased the hot-water extracted soil-B to $1.0 \mathrm{mg} \mathrm{dm}^{-3}$, and total leaf-B to $300 \mathrm{mg} \mathrm{kg}^{-1}$. Soil Zn application was less effective than the leaf spray treatment due to high $\mathrm{Zn}$ adsorption in the soil. Soil testing and leaf analyses calibration curves were determined to establish B and Zn nutrient management program for citrus.
\end{abstract}

Index terms: citrus, micronutrients, fertilizer application, soil fertility, yields.

(1) Aceito para a publicação em 3 de fevereiro de 2003.

(2) Instituto Agronômico, Centro de Solos e Recursos Agroambientais, Caixa Postal 28, CEP 13020-970 Campinas, SP. Bolsista do CNPq. E-mail: quaggio@iac.br, hcantare@iac.br

(3) Instituto Agronômico, Centro de Citricultura Sylvio Moreira, Rodovia Anhangüera km 158, CEP 13490-970 Cordeirópolis, SP. E-mail: ddm@ centrodecitricultura.br

(4) Guacho Agropecuária S.A., Caixa Postal 177, CEP 18900-000 Santa Cruz do Rio Pardo, SP. E-mail: tankjr@novamerica.com.br

\section{Introdução}

As plantas cítricas são exigentes em boro (B), zinco (Zn), manganês (Mn) e ferro (Fe). A deficiência desses micronutrientes é comum na citricultura mundial. A deficiência de Fe restringe-se aos citros cultivados em solos originários de substrato calcário. Em condições tropicais, as deficiências de B e Zn são as mais freqüentes e há escassez de conhecimento sobre doses, modos eficientes de aplicação e critérios 
seguros para o diagnóstico da necessidade de adubação com esses nutrientes, razões pelas quais eles têm limitado a produtividade e a qualidade dos frutos cítricos no Brasil (Quaggio \& Piza Junior, 2001).

A baixa mobilidade no floema limita a redistribuição da maioria dos micronutrientes na planta. Apesar disso, a aplicação de micronutrientes nas plantas cítricas tem sido usualmente feita por meio de pulverizações foliares. Na citricultura, existem pesquisas que demonstram a eficiência da aplicação foliar do Zn, Mn e Fe, porém é necessário aplicá-los a cada fluxo de vegetação nova, já que os nutrientes aplicados na vegetação anterior não se redistribuem para os tecidos novos (Labanauskas et al., 1964; Embleton et al., 1965).

Leonard (1969) comparou em solo muito arenoso e com pouca matéria orgânica, na Florida, EUA, a eficiência das aplicações de Mn no solo e via foliar, e concluiu que duas aplicações foliares anuais, em doses muito inferiores às aplicadas no solo, corrigiram os sintomas de deficiência e mantiveram os teores foliares em níveis adequados. Além disso, a aplicação foliar promoveu aumento na concentração de Mn nas radicelas das plantas tratadas, demonstrando que parte do nutriente aplicado na folha é levada ao solo e permanece por algum tempo disponível para a planta. Nessa mesma área, Smith (1967) testou diferentes fontes e formas de aplicação de $\mathrm{Zn}$ no solo, em doses elevadas (0,5 e 1,0 kg de Zn por planta) e verificou que o $\mathrm{ZnSO}_{4} .7 \mathrm{H}_{2} \mathrm{O}$ foi mais eficiente que o $\mathrm{ZnO}$ na forma de óxidos silicatados (fritas). Dois anos após a aplicação dos tratamentos, os teores foliares de $\mathrm{Zn}$ foram reduzidos em $70 \%$ em relação à amostragem de seis meses, demonstrando que, apesar das doses elevadas, o efeito residual não é prolongado, o que limita a viabilidade econômica dessa prática. Peliser et al. (1993) estudaram, durante três anos, a eficiência da aplicação de B e Zn em solos do Rio Grande do Sul e também constataram que, apesar das altas doses de $\mathrm{Zn}$ aplicadas no solo, não houve reflexo desse nutriente nas folhas em níveis adequados.

A redistribuição do $\mathrm{B}$ é feita basicamente pela corrente transpiratória (Brown \& Shelp, 1997). Em regiões mais frias, onde as plantas apresentam menor taxa de transpiração, a absorção do B é reduzida, agravando os casos de deficiência. Em fruteiras, a deficiência de B causa mau funcionamento do tecido do câmbio vascular, responsável pela multiplicação de células dos vasos condutores, provocando colapso imediato do floema e posteriormente do xilema, quando a deficiência é aguda. Assim, ocorre um menor transporte de fotossintatos para as raízes, que têm o crescimento reduzido, prejudicando a absorção de água e nutrientes. Portanto, o crescimento da planta torna-se também reduzido, conforme observado por Hass \& Klots (1931) e Hass (1945), em citros, na Califórnia, EUA, por Morales \& Muller (1977), em maracujazeiro, e por Parez \& Childers (1983), em mamoeiro. Não há sintomas típicos nas folhas, mas observa-se estrangulamento do tronco ou ramos, a gema apical morre e ocorre superbrotamento de gemas axilares, com perda da dominância apical, proporcionando um formato de roseta nos pontos de crescimento da planta. Como há redução na condução de açúcares para as raízes, os ramos jovens e principalmente os frutos acumulam essas substâncias em bolsas de goma no albedo.

Nos citros, os sintomas de deficiência de B são caracterizados por frutos duros, que caem prematuramente, às vezes com sementes malformadas e que apresentam bolsas de goma no albedo (Smith \& Reuther, 1949; Smith, 1954; Jones \& Smith, 1964). Porém, estes sintomas são observados em condições severas de deficiência, provocando grandes perdas de produtividade das plantas, conforme observado por Quaggio et al. (1996b), em tangerineiras Poncã, no Estado de Minas Gerais.

Os objetivos deste trabalho foram testar a eficiência da aplicação complementar de B e Zn no solo em comparação com a recomendação tradicional da aplicação via foliar e estabelecer curvas de calibração de análises de solo e de folhas com a produtividade da laranjeira Pêra.

\section{Material e Métodos}

O experimento foi instalado na Agropecuária Guacho, região Sul do Estado de São Paulo, num Latossolo Vermelho-Escuro, de textura média, ácido e de baixa fertilidade natural. O clima da região pela classificação de Köppen é do tipo $\mathrm{CFa}$, com verão quente e úmido, inverno mais acentuado e sem estação seca. A temperatura média anual é de $21,6^{\circ} \mathrm{C}$, cerca de $2,0^{\circ} \mathrm{C}$ e $3,0^{\circ} \mathrm{C}$, respectivamente, inferior às regiões centro e norte da citricultura paulista. 
O ensaio foi realizado num talhão plantado em 1995 , com a variedade Pêra sobre limoeiro Cravo, no espaçamento de 7,0x3,5 m. As parcelas possuíam 21 plantas, com linhas simples de bordadura entre linhas e dupla entre plantas. Foram usadas as cinco plantas centrais das parcelas nas avaliações do experimento.

Os tratamentos foram arranjados num delineamento em blocos casualizados em fatorial $4^{2}$, com três repetições, e tiveram início em outubro de 1998. Aplicou-se no solo B (ácido bórico) e Zn (sulfato de zinco), nas doses anuais de $0,2,4$ e $6 \mathrm{~kg} \mathrm{ha}^{-1}$ do nutriente. Essas doses foram parceladas em três aplicações anuais, durante a primavera e verão, com a adubação N, P e K. Todas as parcelas, inclusive as testemunhas sem $\mathrm{Zn}$ e B no solo, receberam, via foliar, uma calda composta por uréia $\left(3,0 \mathrm{~g} \mathrm{~L}^{-1}\right)$, sulfato de zinco $\left(5,0 \mathrm{~g} \mathrm{~L}^{-1}\right)$ e ácido bórico $\left(2,0 \mathrm{~g} \mathrm{~L}^{-1}\right)$. As aplicações foliares foram bianuais, uma na floração e a outra em pleno verão, geralmente no mês de dezembro.

A produção e a qualidade dos frutos foram avaliadas em três safras consecutivas. Na época da colheita principal, foram colhidos 10 frutos por planta, sete externamente na copa e três dentro dela, num total de 50 frutos por parcela, para determinação do teor de sólidos solúveis totais, da acidez titulável, do teor de vitamina $\mathrm{C}$ e da cor do suco (Reed et al., 1986). Durante o período experimental, realizaram-se análises de solo e folhas, conforme Bataglia et al. (1983) e Raij et al. (2001). Os dados obtidos foram submetidos às análises de variância e de regressão, executadas pelo programa Minitab, versão 13 (Minitab Inc., 2000).

\section{Resultados e Discussão}

As doses de B aplicadas no solo proporcionaram ganhos de produtividade em relação ao tratamento convencional de aplicação foliar (Tabela 1). Resposta significativa e linear à aplicação de B no solo foi observada a partir do segundo ano, ao passo que no terceiro ano da aplicação, a resposta obedeceu ao modelo quadrático. Na safra 2001, a distribuição irregular das chuvas após a floração prejudicou a produtividade. Por essa razão, a produção média desta safra foi bem inferior à da safra anterior (Tabela 1). A maior amplitude de resposta ao B aplicado no solo ocorreu no ano mais seco (2001), o que deve estar relacionado à função do $\mathrm{B}$ na formação dos vasos condutores da planta e, conseqüentemente, ao desenvolvimento do sistema radicular (Hass \& Klots, 1931; Hass, 1945).
Resposta significativa ao $\mathrm{Zn}$ foi observada apenas no terceiro ano após o início da aplicação dos tratamentos. Embleton et al. (1965) constataram efeito do $\mathrm{Zn}$ aplicado no solo somente no segundo ano após a sua aplicação. A interação entre doses de B e $\mathrm{Zn}$ foi significativa. Assim, na presença da dose máxima de $\mathrm{B}$, houve efeito depressivo em relação às doses de $\mathrm{Zn}$ aplicadas no solo ao passo que resposta positiva, porém pouco expressiva, foi obtida na presença da dose de $2 \mathrm{~kg} \mathrm{ha}^{-1}$ de B (Figura 1).

A aplicação de $\mathrm{Zn}$ no solo tem eficiência muito baixa quando comparada com a sua aplicação via foliar, apesar da baixa redistribuição desse nutriente nas folhas e nos ramos novos (Labanauskas et al., 1964; Embleton et al., 1965). Esses resultados são coerentes com os de Smith (1967), que testou durante três anos, num pomar de laranjeiras Valência com sintomas visíveis de deficiência de Zn na Flórida, EUA, doses de 100 e $200 \mathrm{~kg} \mathrm{ha}^{-1}$ de Zn e não obteve resposta significativa em produção. Com base na análise foliar, o autor concluiu que houve efeito residual prolongado dessas doses elevadas. Entretanto, os teores foliares no primeiro ano foram o dobro dos observados no terceiro ano após a aplicação dos tratamentos, o que demonstra alta capacidade de adsorção de $\mathrm{Zn}$, mesmo em um solo extremamente arenoso. Resultados semelhantes, com doses elevadas de Mn, foram observados por Leonard (1969) na Flórida, e Peliser et al. (1993), em experimento com laranjeira Valência no Rio Grande do Sul.

Tabela 1. Produção $\left(\mathrm{t} \mathrm{ha}^{-1}\right)$ de frutos de laranjeira Pêra em resposta à aplicação de $\mathrm{B} e \mathrm{Zn}$, em diferentes doses no solo, em complementação à adubação foliar.

\begin{tabular}{cccc}
\hline $\begin{array}{c}\text { Nutriente } \\
\left(\mathrm{kg} \mathrm{ha}^{-1}\right)\end{array}$ & 1999 & 2000 & 2001 \\
\hline $\begin{array}{c}\text { Boro } \\
0\end{array}$ & 27,2 & 34,2 & 19,5 \\
2 & 28,5 & 37,8 & 27,3 \\
4 & 28,6 & 38,6 & 28,0 \\
6 & 29,0 & 40,5 & 22,0 \\
\hline Teste F & $0,4^{\text {ns }}$ & $5,6^{* *}$ & $11,3^{* *}$ \\
\hline Zinco & & & \\
0 & 29,3 & 36,7 & 26,8 \\
2 & 25,7 & 34,7 & 22,0 \\
4 & 29,2 & 35,0 & 21,5 \\
6 & 29,0 & 38,6 & 26,6 \\
\hline Teste F & $2,0^{\text {ns }}$ & $1,6^{\text {ns }}$ & $5,4^{* *}$ \\
\hline${ }^{n}$ Não-significativo. ${ }^{* *}$ Significativo a $1 \%$ de probabilidade.
\end{tabular}

Pesq. agropec. bras., Brasília, v. 38, n. 5, p. 627-634, maio 2003 
Os efeitos dos tratamentos na qualidade dos frutos foram significativos apenas com as doses de B (Tabela 2). Maiores doses de B proporcionaram aumento do tamanho e redução no teor de açúcares nos frutos, o que refletiu em menor rendimento industrial, ou seja, menor quantidade de sólidos solúveis por caixa. Os teores de suco e vitamina $\mathrm{C}$ foram também reduzidos pelas doses de B apenas na safra de alta produtividade, em 2000. Provavelmente os efeitos do B sobre essas características de qualida-

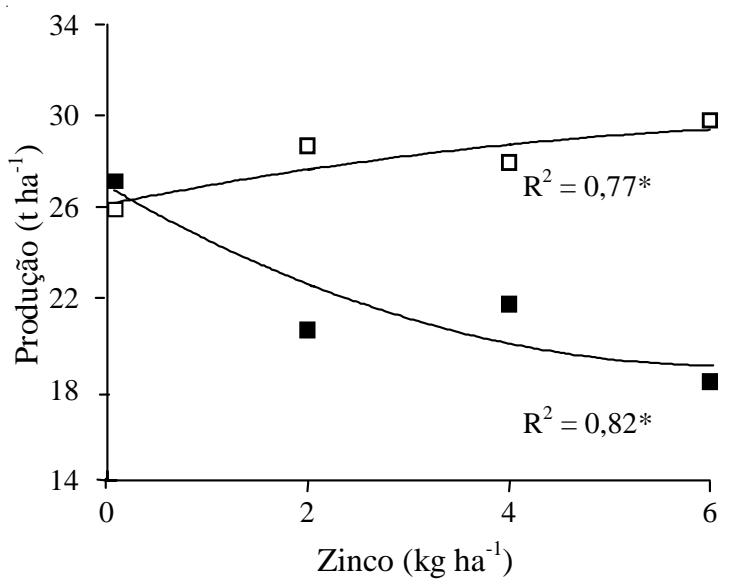

Figura 1. Efeito da aplicação no solo de $2 \mathrm{~kg} \mathrm{ha}^{-1} \mathrm{de} B(\square)$ e $6 \mathrm{~kg} \mathrm{ha}^{-1} \mathrm{de} \mathrm{Zn}$ (ロ) em complementação à adubação foliar, na produtividade da laranjeira Pêra, em 2001. *Significativo a $5 \%$ de probabilidade. de dos frutos podem estar relacionados à maior disponibilidade de potássio $(\mathrm{K})$ verificada no solo (Tabela 3) e nas folhas (Tabela 4), nos tratamentos com as maiores doses de boro. Os efeitos do $\mathrm{K}$ sobre essas características dos frutos cítricos são muito consistentes na literatura (Quaggio et al., 2002). Os teores de $\mathrm{Zn}$ não proporcionaram nenhum efeito significativo na qualidade dos frutos.

As doses de B proporcionaram aumentos no seu teor no solo nas duas épocas de amostragem, sempre com reflexos significativos nas folhas. Entretanto, as doses de $\mathrm{Zn}$, provocaram aumento no seu teor no solo, já seis meses após a sua aplicação, porém sem resposta nas folhas (Figura 2). Dois anos após a aplicação dos tratamentos, observou-se estreita correlação entre os teores de $\mathrm{Zn}$ no solo e nas folhas (Figura 3). Isso mostra que esse nutriente, quando aplicado no solo, requer tempo para ser absorvido pela planta, conforme observado por Embleton et al. (1965) em solos argilosos da Califórnia, EUA. Por outro lado, Smith (1967) observou acréscimos nos teores de $\mathrm{Zn}$ nas folhas nos primeiros meses após a sua aplicação no solo. Essa discrepância talvez possa ser explicada não somente por diferenças entre os solos, mas também pela idade das plantas e irrigação. O experimento de Smith (1967), além de ser irrigado, foi realizado com plantas adultas, com copas bem desenvolvidas que sombreavam o solo. Esses fatos propiciam melhores condições de umi-

Tabela 2. Qualidade dos frutos de laranjeira Pêra, cultivada em solo adubado com doses de B, em complementação à adubação foliar nas safras de 2000 e $2001^{(1)}$.

\begin{tabular}{ccccccccc}
\hline $\begin{array}{c}\text { Boro } \\
\left(\mathrm{kg} \mathrm{ha}^{-1}\right)\end{array}$ & $\begin{array}{c}\text { Massa } \\
(\mathrm{g})\end{array}$ & $\begin{array}{c}\text { SST } \\
(\%)\end{array}$ & $\begin{array}{c}\text { Acidez } \\
(\%)\end{array}$ & $\begin{array}{c}\text { SST/cx } \\
(\mathrm{kg})\end{array}$ & $\begin{array}{c}\text { Relação } \\
\text { B/A }\end{array}$ & $\begin{array}{c}\text { Suco } \\
(\%)\end{array}$ & $\begin{array}{c}\text { Vit. C } \\
(\mathrm{mg})\end{array}$ & Cor \\
\hline & & & \multicolumn{7}{c}{2000} & & & & \\
0 & 125,7 & 11,6 & 0,66 & 2,83 & 17,8 & 59,8 & 35,3 & 37 \\
2 & 121,3 & 11,4 & 0,64 & 2,76 & 17,7 & 59,3 & 35,6 & 37 \\
4 & 124,6 & 11,5 & 0,63 & 2,74 & 18,0 & 58,6 & 35,3 & 36 \\
6 & 135,3 & 11,0 & 0,64 & 2,72 & 17,3 & 60,4 & 35,6 & 36 \\
\hline Teste F & $6,3^{* *}$ & $3,9^{*}$ & $0,4^{\text {ns }}$ & $2,2^{*}$ & $0,9^{\text {ns }}$ & $1,2^{\text {ns }}$ & $0,4^{\text {ns }}$ & $0,3^{\text {ns }}$ \\
\hline & & & \multicolumn{7}{c}{2001} & & & \\
0 & 126,1 & 9,9 & 0,61 & 2,52 & 16,3 & 62,3 & 37,4 & 38 \\
2 & 122,8 & 9,8 & 0,59 & 2,42 & 16,5 & 60,6 & 35,7 & 38 \\
4 & 125,4 & 9,8 & 0,60 & 2,47 & 16,5 & 62,1 & 36,7 & 38 \\
6 & 135,9 & 9,2 & 0,56 & 2,26 & 16,5 & 60,3 & 34,8 & 38 \\
\hline Teste F & $5,3^{* *}$ & $10,4^{* *}$ & $3,8^{*}$ & $7,6^{* *}$ & $0,2^{\text {ns }}$ & $3,5^{*}$ & $2,4^{*}$ & $1,2^{\text {ns }}$ \\
\hline
\end{tabular}

${ }^{(1)}$ SST: sólidos solúveis totais; SST/cx: sólidos solúveis totais por caixa; B/A: relação Brix/acidez; Vit. C: teor de vitamina C. ${ }^{n s}$ Não-significativo

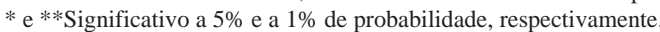


dade para a absorção do $\mathrm{Zn}$, enquanto no início do presente trabalho as plantas eram jovens, apresentavam copa pouco desenvolvida e não havia irrigação.

Os teores de B e Zn no solo, tanto na camada arável como na camada de $20-40 \mathrm{~cm}$, no terceiro ano de realização do experimento, estiveram estreitamente relacionados com os teores nas folhas (Figura 3). Isso mostra que ambos os nutrientes estão sujeitos à lixiviação. O B, por estar presente no solo predominantemente na forma de ácido bórico, portanto não iônica, tem movimento muito mais rápido do que o zinco. Na amostragem de solo realizada em 2001, os teores de B na camada de 20-40 cm foram superiores aos observados na camada arável. Além disso, o B não se acumulou no solo entre 1999 e 2001 e sua aplicação apenas na folha não foi suficiente para elevar o seu teor no solo acima de $0,4 \mathrm{mg} \mathrm{dm}^{-3}$ (Tabe- la 3). Esses resultados sugerem que, para melhor eficiência da adubação, o B deve ser aplicado parceladamente, devido ao seu grande potencial de perdas por lixiviação.

A movimentação do $\mathrm{Zn}$, com o passar do tempo, para as camadas mais profundas do solo, que mantêm maior disponibilidade de água, parece ser fundamental para assegurar a sua absorção pela planta cítrica e explica também a falta de correlação observada entre os teores de $\mathrm{Zn}$ no solo e nas folhas, no primeiro ano do experimento (Figura 2). Ao contrário do B, a aplicação foliar do Zn promoveu seu acúmulo no solo (de 1,4 mg kg-1 em 1999 para 2,5 mg kg-1 em 2001), demonstrando que boa parte desse nutriente aplicado nas folhas é lavado pelas águas de chuva ou escorre diretamente para o solo (Tabela 3). Isso pode explicar a eficiência da aplicação foliar do Zn, apesar de pequena redistribuição dentro da planta,

Tabela 3. Características químicas da camada arável do solo após aplicação de doses de boro e de zinco, em duas épocas de amostragem (1999 e 2001).

\begin{tabular}{|c|c|c|c|c|c|c|c|c|c|}
\hline $\begin{array}{c}\text { Boro } \\
\left(\mathrm{kg} \mathrm{ha}^{-1}\right)\end{array}$ & $\begin{array}{c}\mathrm{MO} \\
\left(\mathrm{g} \mathrm{dm}^{-3}\right)\end{array}$ & $\mathrm{pH}$ & $\begin{array}{l}\text { P-resina } \\
\left(\mathrm{mg} \mathrm{dm}^{-3}\right)\end{array}$ & $\begin{array}{c}\mathrm{K}^{+} \\
-\end{array}$ & $\begin{array}{c}\mathrm{Ca}^{2+} \\
--(\mathrm{mmo} \\
\end{array}$ & $\begin{array}{l}\mathrm{Mg}^{2+} \\
\left(\mathrm{m}^{-3}\right)^{---}\end{array}$ & $\mathrm{H}+\mathrm{Al}$ & $\begin{array}{l}\mathrm{V} \\
(\%)\end{array}$ & $\begin{array}{c}\mathrm{B} \\
\left(\mathrm{mg} \mathrm{dm}^{-3}\right)\end{array}$ \\
\hline & \multicolumn{9}{|c|}{1999} \\
\hline 0 & 26 & 5,3 & 45 & 0,5 & 45 & 25 & 34 & 66 & 0,3 \\
\hline 2 & 25 & 5,4 & 45 & 0,4 & 45 & 27 & 33 & 67 & 0,9 \\
\hline 4 & 26 & 5,5 & 48 & 0,4 & 44 & 25 & 35 & 65 & 1,4 \\
\hline 6 & 27 & 5,3 & 47 & 0,8 & 49 & 27 & 33 & 68 & 1,7 \\
\hline \multirow[t]{2}{*}{ Teste F } & $0,8^{\mathrm{ns}}$ & $0,7^{\mathrm{ns}}$ & $0,1^{\mathrm{ns}}$ & $2,0^{\mathrm{ns}}$ & $0,2^{\mathrm{ns}}$ & $0,2^{\mathrm{ns}}$ & $0,7^{\mathrm{ns}}$ & $0,4^{\mathrm{ns}}$ & $26,2 * *$ \\
\hline & \multicolumn{9}{|c|}{2001} \\
\hline 0 & 22 & 4,9 & 34 & 2,8 & 24 & 7 & 39 & 47 & 0,4 \\
\hline 2 & 23 & 4,9 & 39 & 3,3 & 26 & 7 & 38 & 50 & 1,1 \\
\hline 4 & 23 & 5,1 & 26 & 3,2 & 29 & 9 & 34 & 54 & 1,3 \\
\hline 6 & 24 & 5,2 & 35 & 3,7 & 30 & 9 & 34 & 55 & 1,6 \\
\hline Teste F & $1,7^{\mathrm{ns}}$ & $2,8^{*}$ & $1,7^{\mathrm{ns}}$ & $3,5^{*}$ & $1,9^{\text {ns }}$ & $1,3^{\mathrm{ns}}$ & $1,4^{\mathrm{ns}}$ & $2,3^{*}$ & $54,3 * *$ \\
\hline \multirow{3}{*}{$\begin{array}{c}\text { Zinco } \\
\left(\mathrm{kg} \mathrm{ha}^{-1}\right) \\
\end{array}$} & MO & $\mathrm{pH}$ & P-resina & $\mathrm{K}^{+}$ & $\mathrm{Ca}^{2+}$ & $\mathrm{Mg}^{2+}$ & $\mathrm{H}+\mathrm{Al}$ & $\mathrm{V}$ & $\mathrm{Zn}$ \\
\hline & $\left(\mathrm{g} \mathrm{dm}^{-3}\right)$ & & $\left(\mathrm{mg} \mathrm{dm} \mathrm{m}^{-3}\right)$ & & & $\left(\mathrm{m}^{-3}\right)$ & & $(\%)$ & $\left(\mathrm{mg} \mathrm{dm}^{-3}\right)$ \\
\hline & \\
\hline 0 & 26 & 5,0 & 41 & 4,8 & 41 & 23 & 37 & 63 & 1,4 \\
\hline 2 & 26 & 5,2 & 49 & 7,0 & 45 & 24 & 34 & 64 & 3,1 \\
\hline 4 & 26 & 5,2 & 54 & 4,7 & 54 & 32 & 32 & 71 & 6,6 \\
\hline 6 & 25 & 5,1 & 41 & 4,9 & 44 & 25 & 32 & 67 & 7,2 \\
\hline \multirow[t]{2}{*}{ Teste F } & $0,8^{\text {ns }}$ & $0,7^{\mathrm{ns}}$ & $0,1^{\mathrm{ns}}$ & $1,0^{\mathrm{ns}}$ & $0,4^{\mathrm{ns}}$ & $1,2^{\mathrm{ns}}$ & $0,8^{\text {ns }}$ & $0,7^{\mathrm{ns}}$ & $7,2 * *$ \\
\hline & \multicolumn{9}{|c|}{2001} \\
\hline 0 & 24 & 5,0 & 37 & 3,3 & 26 & 7 & 37 & 50 & 2,5 \\
\hline 2 & 23 & 5,0 & 40 & 3,3 & 28 & 8 & 38 & 50 & 4,7 \\
\hline 4 & 23 & 5,0 & 32 & 3,2 & 28 & 9 & 34 & 54 & 6,3 \\
\hline 6 & 22 & 5,0 & 35 & 3,1 & 27 & 8 & 36 & 51 & 12,4 \\
\hline Teste F & $1,1^{\mathrm{ns}}$ & $0,8^{\mathrm{ns}}$ & $1,7^{\mathrm{ns}}$ & $0,5^{\mathrm{ns}}$ & $1,0^{\mathrm{ns}}$ & $1,1^{\mathrm{ns}}$ & $0,4^{\mathrm{ns}}$ & $0,3^{\text {ns }}$ & $10,7 * *$ \\
\hline
\end{tabular}

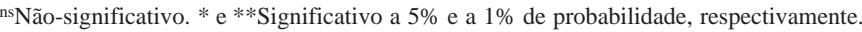


Tabela 4. Concentração de macronutrientes e micronutrientes nas folhas da laranjeira Pêra em três safras consecutivas, após a aplicação de doses de boro, em diferentes doses, em complementação à aplicação foliar, em três épocas de amostragem (1999, 2000 e 2001).

\begin{tabular}{|c|c|c|c|c|c|c|c|c|c|c|}
\hline \multirow{2}{*}{$\begin{array}{c}\text { Boro } \\
\left(\mathrm{kg} \mathrm{ha}^{-1}\right)\end{array}$} & $\mathrm{N}$ & $\mathrm{K}$ & $\mathrm{P}$ & $\mathrm{Ca}$ & $\mathrm{Mg}$ & B & $\mathrm{Cu}$ & $\mathrm{Fe}$ & $\mathrm{Mn}$ & $\mathrm{Zn}$ \\
\hline & & & 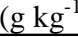 & & & & & $\mathrm{ng} \mathrm{kg}^{-}$ & & \\
\hline & \multicolumn{10}{|c|}{1999} \\
\hline 0 & 32,0 & 7,1 & 2,1 & 34,8 & 5,7 & 63 & 5 & 99 & 21 & 12 \\
\hline 2 & 32,0 & 7,1 & 2,1 & 35,7 & 5,8 & 141 & 7 & 102 & 21 & 12 \\
\hline 4 & 29,2 & 7,8 & 2,1 & 35,1 & 5,7 & 292 & 13 & 103 & 19 & 12 \\
\hline 6 & 31,2 & 9,7 & 2,0 & 34,3 & 5,6 & 348 & 6 & 102 & 18 & 13 \\
\hline \multirow[t]{2}{*}{ Teste F } & $0,9^{\mathrm{ns}}$ & $2,7 *$ & $0,3^{\mathrm{ns}}$ & $0,5^{\mathrm{ns}}$ & $0,2^{\mathrm{ns}}$ & $192 * *$ & $1,8^{\mathrm{ns}}$ & $0,7^{\mathrm{ns}}$ & $2,4 *$ & $0,3^{\mathrm{ns}}$ \\
\hline & \multicolumn{10}{|c|}{2000} \\
\hline 0 & 27,7 & 6,8 & 1,3 & 36,6 & 4,0 & 70 & 14 & 125 & 64 & 29 \\
\hline 2 & 28,4 & 7,2 & 1,4 & 36,3 & 4,0 & 217 & 14 & 144 & 65 & 30 \\
\hline 4 & 27,5 & 8,1 & 1,3 & 34,5 & 3,9 & 308 & 14 & 131 & 71 & 34 \\
\hline 6 & 27,5 & 9,0 & 1,3 & 37,2 & 3,8 & 334 & 13 & 187 & 63 & 32 \\
\hline \multirow[t]{2}{*}{ Teste F } & $1,3^{\mathrm{ns}}$ & $7,8 * *$ & $0,1^{\mathrm{ns}}$ & $1,1^{\mathrm{ns}}$ & $0,9^{\text {ns }}$ & $102 * *$ & $0,3^{\mathrm{ns}}$ & $1,1^{\mathrm{ns}}$ & $0,9^{\mathrm{ns}}$ & $1,2^{\mathrm{ns}}$ \\
\hline & \multicolumn{10}{|c|}{2001} \\
\hline 0 & 31,9 & 7,8 & 1,5 & 42,1 & 4,6 & 64 & 16 & 138 & 70 & 35 \\
\hline 2 & 32,6 & 8,3 & 1,6 & 41,8 & 4,6 & 229 & 15 & 158 & 71 & 35 \\
\hline 4 & 31,6 & 9,3 & 1,5 & 39,7 & 4,4 & 329 & 15 & 144 & 78 & 40 \\
\hline 6 & 31,7 & 10,3 & 1,5 & 42,8 & 4,3 & 358 & 15 & 147 & 70 & 38 \\
\hline Teste F & $1,4^{\mathrm{ns}}$ & $7,7 * *$ & $0,2^{\mathrm{ns}}$ & $1,0^{\mathrm{ns}}$ & $1,1^{\mathrm{ns}}$ & $103 * *$ & $0,3^{\mathrm{ns}}$ & $0,3^{\mathrm{ns}}$ & $1,1^{\mathrm{ns}}$ & $0,9^{\text {ns }}$ \\
\hline
\end{tabular}

ns Não-significativo. $*$ e **Significativo a $5 \%$ e a $1 \%$ de probabilidade, respectivamente.

pois o aumento da disponibilidade desse nutriente no solo deve ser suficiente para o seu suprimento às novas brotações, posteriores à aplicação foliar.

As doses de Zn não afetaram as concentrações foliares de outros nutrientes (Tabela 4). Apenas a aplicação foliar do $\mathrm{Zn}$ foi suficiente para manter os teores foliares dentro da faixa considerada normal em citros (Quaggio et al., 1996a). Os teores foliares de B mantiveram-se dentro da faixa considerada normal em citros, ou seja, entre 36 e $100 \mathrm{mg} \mathrm{kg}^{-1}$ (Quaggio et al., 1996a) somente com a aplicação foliar. A produtividade máxima, porém, ocorreu com a dose de $4 \mathrm{~kg} \mathrm{ha}^{-1}$ de B aplicada no solo (Tabela 1), que elevou o seu teor foliar para valores entre $280 \mathrm{e}$ $320 \mathrm{mg} \mathrm{kg}^{-1}$. Esses teores podem ser considerados tóxicos, de acordo com Mattos Junior et al. (1995), em mudas cítricas. No presente trabalho, observouse apenas sintomas moderados de toxicidade de B na safra 2001, nas parcelas que receberam $6 \mathrm{~kg} \mathrm{ha}^{-1}$ de $B$, suficiente para elevar o seu teor foliar para $358 \mathrm{mg} \mathrm{kg}^{-1}$.

As doses de B aplicadas no solo, além de provocar acréscimo linear no teor foliar, afetaram também a concentração de $\mathrm{K}$, de modo consistente nos três anos (Tabela 4). Provavelmente, isto é reflexo da maior disponibilidade de K na camada arável, observada 24 meses após a aplicação das doses de B no
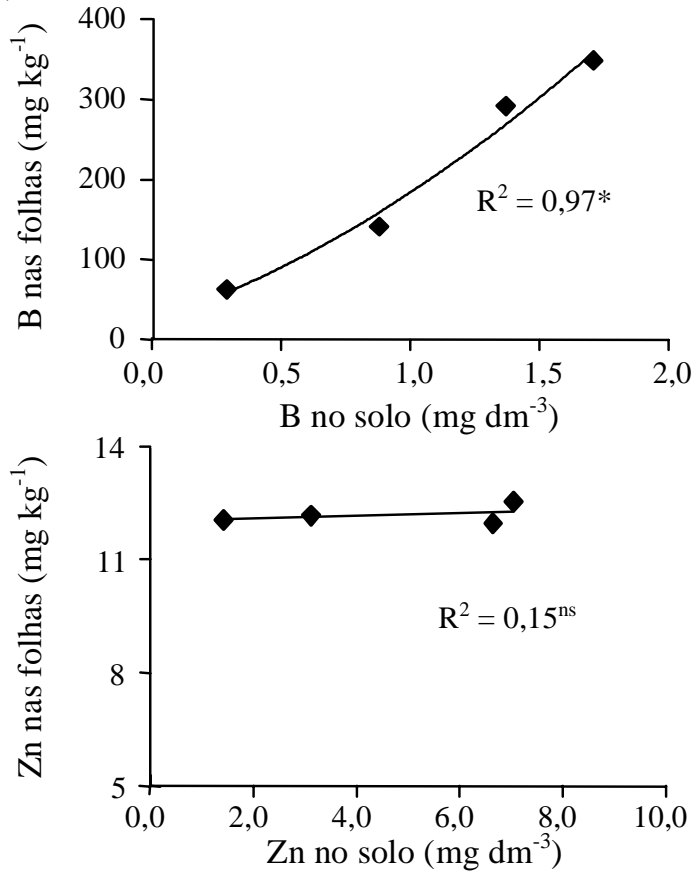

Figura 2. Correlações entre os teores de boro e zinco no solo $(0-20 \mathrm{~cm})$ e nas folhas de laranjeira Pêra, seis meses

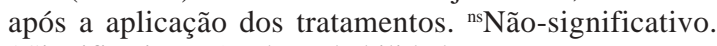
*Significativo a $5 \%$ de probabilidade. 

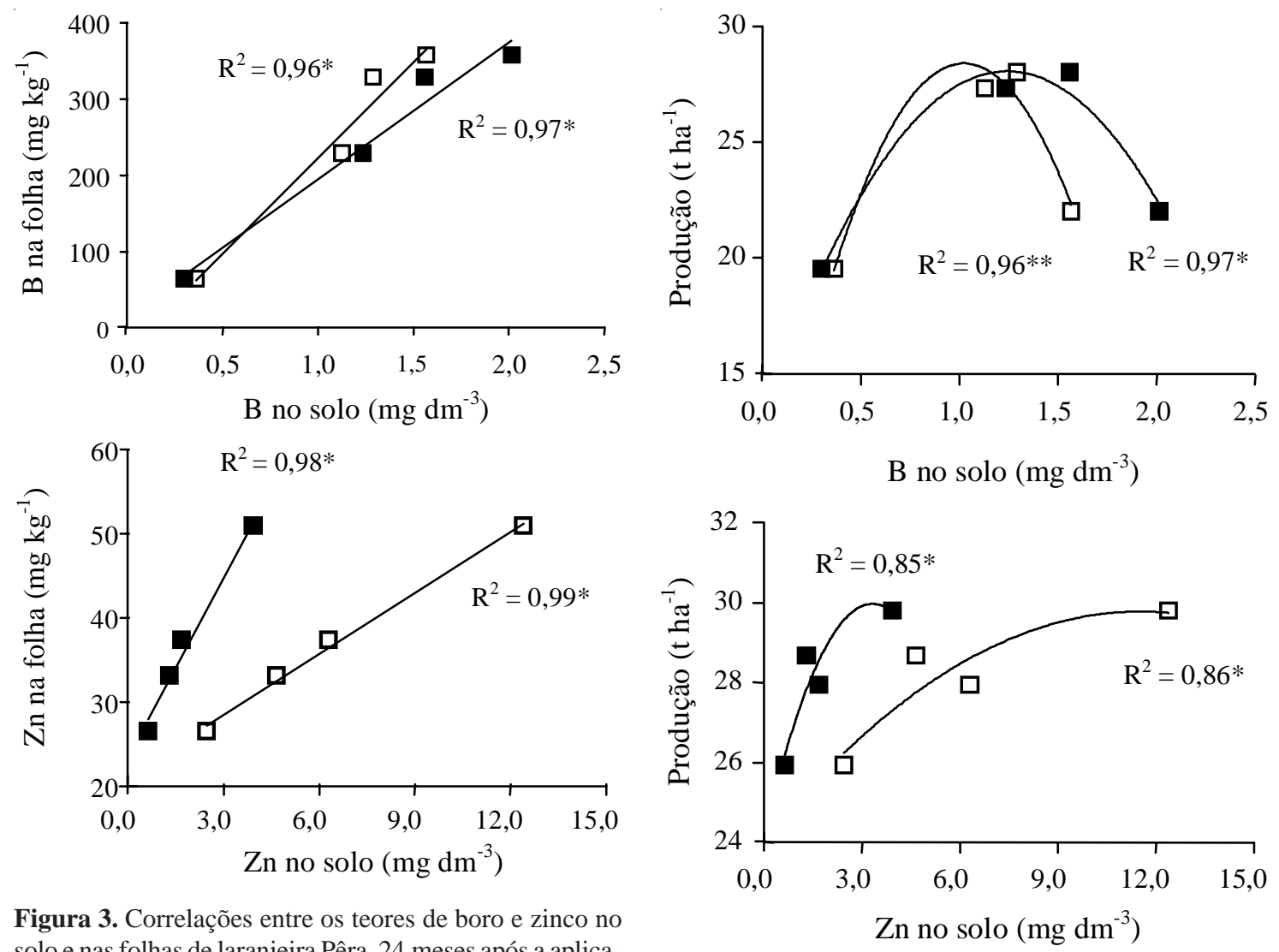

Figura 3. Correlações entre os teores de boro e zinco no solo e nas folhas de laranjeira Pêra, 24 meses após a aplicação dos tratamentos, nas profundidades de 0-20 cm ( $\square$ ) e 20-40 cm (ם). *Significativo a 5\% de probabilidade.

solo, as quais afetaram também o pH e a saturação por bases do solo na mesma proporção que o K (Tabela 3). Não há uma explicação clara sobre a relação entre causa e efeito nestes resultados.

A produção máxima foi obtida com teores no solo de 1,0 e $1,3 \mathrm{mg} \mathrm{dm}^{-3}$ de $\mathrm{B}$, respectivamente, nas camadas de 0-20 cm e 20-40 cm (Figura 4). Esses valores são superiores aos usados na interpretação de análises de solo em relação ao B no Estado de São Paulo, definidos para culturas anuais (Raij et al., 1996). Quanto aos teores baixos, há coerência na interpretação, conforme já comprovado anteriormente por Quaggio et al. (1996b) com tangerineiras Poncã deficientes em boro.

Como foi observada interação negativa entre doses de Zn e B no solo na safra de 2001 (Figura 1), a

Figura 4. Calibração de análises de boro e zinco no solo, nas profundidades de $0-20 \mathrm{~cm}(\square)$ e $20-40 \mathrm{~cm}(\mathbf{\square})$ e produtividade da laranjeira Pêra, em 2001. * e**Significativo, a $5 \%$ e a $1 \%$ de probabilidade, respectivamente.

curva de calibração em relação aos teores de Zn no solo foi ajustada com as produtividades da laranjeira Pêra obtidas nos tratamentos com $2 \mathrm{~kg} \mathrm{ha}^{-1} \mathrm{de} \mathrm{B} \mathrm{(Fi-}$ gura 4). A produtividade máxima foi alcançada com 3,0 $\mathrm{mg} \mathrm{dm}^{-3}$ de $\mathrm{Zn}$ no solo na camada de $0-20 \mathrm{~cm}$, demonstrando também que esse teor é superior aos das culturas anuais (Raij et al., 1996).

\section{Conclusões}

1. A adubação complementar com B no solo foi mais eficiente do que a aplicação via foliar para a laranjeira Pêra.

2. A aplicação via foliar de Zn na laranjeira Pêra é mais eficiente do que a aplicação no solo. 


\section{Agradecimentos}

Ao CNPq, pelas bolsas de produtividade em pesquisa; à Fapesp, pelo apoio financeiro; a Guacho Agropecuária S.A., pelo suporte de campo.

\section{Referências}

BATAGLIA, O. C.; FURLANI, A. M. C.; TEIXEIRA, J. P. F.; FURLANI, P. R.; GALLO, J. R. Métodos de análise química de plantas. Campinas: Instituto Agronômico, 1983. 48 p. (Boletim Técnico, 78).

BROWN, P.; SHELP, B. J. Boron mobility in plants. Plant and Soil, Dordrecht, v. 193, p. 85-101, 1997.

EMBLETON, T. W.; WALLIHAN, E. F.; GOODALL, G. E. Effectiveness of soil vs. foliar applied zinc and of foliar applied manganese on California lemons. American Society for Horticultural Science Proceedings, Alexandria, v. 86, p. 253-259, 1965.

HASS, A. R. C. Boron in citrus trees. Plant Physiology, Rockville, v. 20, p. 323-343, 1945.

HASS, A. R. C.; KLOTS, L. J. Some anatomical and physiological changes in citrus produced by born deficiency. Hilgardia, Berkeley, v. 5, p. 175-196, 1931.

JONES, W. W.; SMITH, P. Nutrient deficiency in citrus. In: HOWARD, B.; SPRAUGUE, H. B. (Ed.). Hunger signs in crops. 3rd ed. New York: D. Mc Kay, 1964. p. 353-383.

LABANAUSKAS, C. K.; JONES, W. W.; EMBLETON, T. W. Effects of foliar applications of manganese, zinc and urea on yield and fruit quality of Valencia oranges and nutrient concentrations in the leave, peel and juice. American Society for Horticultural Science Proceedings, Alexandria, v. 82, p. 143-153, 1964.

LEONARD, C. D. A comparison of soil and spray applications of four manganese sources for control of manganese deficiency in Valencia orange trees. Proceedings of the Florida State Horticultural Society, Tallahassee, v. 80, p. 12-20, 1969.

MATTOS JUNIOR, D.; QUAGGIO, J. A.; CARVALHO, S. A.; ABREU, M. F. Substratos para produção de mudas cítricas em recipientes: caracterização da toxicidade de boro. Laranja, Cordeirópolis, v. 16, p. 255-262, 1995.

MINITAB INC. (State College, Estados Unidos). User's guide 2: data analysis and quality tools: release 13 . State College, 2000. $752 \mathrm{p}$.

MORALES, A. A.; MULLER, L. E. Alteraciones producidas en maracuya (Passiflora edulis) por deficiencias de manganeso, hierro, boro y zinc. Turrialba, San José, v. 27 , p. $163-168,1977$.
PAREZ, A.; CHILDERS, N. Growth, yield, nutrient content and fruit quality of Carica papaya $\mathrm{L}$. under controlled condition - II: boron effects. Journal of Agriculture of the University of Puerto Rico, San Juan, v. 66, p. 80-88, 1983.

PELISER, O.; KOLLER, O. C.; ANGHINONI, I. Rendimento e qualidade de frutos da laranjeira Valência submetida à adubação com magnésio, manganês, zinco e boro no solo. Revista Brasileira de Fruticultura, Jaboticabal, v. 15 , p. $55-61,1993$.

QUAGGIO, J. A.; MATTOS JUNIOR, D.; CANTARELLA, H.; ALMEIDA, E. L. E.; CARDOSO, S. A. B. Lemon yield and fruit quality affected by NPK fertilization. Scientia Horticulturae, Amsterdam, v. 1836, p. 1-12, 2002.

QUAGGIO, J. A.; PIZA JUNIOR, C. T. Micronutrientes para frutíferas tropicais. In: FERREIRA, M. E.; CRUZ, M. C. P.; RAIJ, B. van; ABREU, C. A. (Ed.). Micronutrientes tóxicos e metais pesados na agricultura. Jaboticabal: CNPq/Fapesp/Potafos, 2001. p. 459-491.

QUAGGIO, J. A.; RAIJ, B. van; PIZA JUNIOR, C. T. Frutíferas. In: RAIJ, B. van; CANTARELLA, H.; QUAGGIO, J. A.; FURLANI, A. M. C. (Ed.). Recomendações de adubação e calagem para o Estado de São Paulo. 2. ed. Campinas: Instituto Agronômico, 1996a. p. 121-153.

QUAGGIO, J. A.; ROSSETTI, V.; CHAGAS, C. M. Anormalidades de tangerineiras Poncã no Estado de Minas Gerais, provocadas por deficiência de boro. Bragantia, Campinas, v. 55, p. 157-162, $1996 \mathrm{~b}$.

RAIJ, B. van; ANDRADE, J. C.; CANTARELLA, H.; QUAGGIO, J. A. Análise química para avaliação da fertilidade de solos tropicais. Campinas: Instituto Agronômico, 2001. 285 p.

RAIJ, B. van; CANTARELLA, H.; QUAGGIO, J. A.; FURLANI, A. M. C. Recomendações de adubação e calagem no Estado de São Paulo. 2. ed. Campinas: Instituto Agronômico, 1996. 300 p.

REED, J. B.; HENDRIX JUNIOR, C. M.; HENDRIX, D. L. Quality control manual for citrus processing plants. Safety Harbour: Intercit, 1986. v. 1.

SMITH, P. Boron deficiency in Florida citrus groves. Proceedings of the Florida State Horticultural Society, Tallahassee, v. 67, p. 69-73, 1954.

SMITH, P. Effect of soil placement, rate and source of applied zinc on the concentration of zinc in Valencia orange leaves. Soil Science, Baltimore, v. 103, p. 209-212, 1967. SMITH, P.; REUTHER, W. Observations on boron deficiency in citrus. Proceedings of the Florida State Horticultural Society, Tallahassee, v. 62, p. 21-37, 1949. 